\title{
Development and validation of a brief dementia screening indicator for primary care
}

\author{
Deborah E. Barnes ${ }^{\mathrm{a}, \mathrm{c}, \mathrm{d}, *}$, Alexa S. Beiser ${ }^{\mathrm{f}, \mathrm{g}}$, Anne Lee ${ }^{\mathrm{c}}$, Kenneth M. Langa $^{\mathrm{h}, \mathrm{i}, \mathrm{j}}$, Alain Koyama ${ }^{\mathrm{e}}$, \\ Sarah R. Preis ${ }^{\mathrm{f}}$, John Neuhaus ${ }^{\mathrm{c}}$, Ryan J. McCammon ${ }^{\mathrm{h}}$, Kristine Yaffe ${ }^{\mathrm{a}, \mathrm{b}, \mathrm{c}, \mathrm{d}}$, Sudha Seshadri ${ }^{\mathrm{f}, \mathrm{g}}$, \\ Mary N. Haan ${ }^{\mathrm{c}}$, David R. Weir ${ }^{\mathrm{h}}$ \\ ${ }^{a}$ Department of Psychiatry, University of California, San Francisco, CA, USA \\ ${ }^{b}$ Department of Neurology, University of California, San Francisco, CA, USA \\ ${ }^{c}$ Department of Epidemiology \& Biostatistics, University of California, San Francisco, CA, USA \\ ${ }^{d}$ Veterans Affairs Medical Center, San Francisco, CA, USA \\ ${ }^{e}$ Northern California Institute for Research and Education, San Francisco, CA, USA \\ ${ }^{f}$ Department of Neurology, Boston University, Boston, MA, USA \\ ${ }^{g}$ Department of Biostatistics, Boston University, Boston, MA, USA \\ ${ }^{h}$ Institute for Social Research, University of Michigan, Ann Arbor, MI, USA \\ ${ }^{i}$ Department of Medicine, University of Michigan, Ann Arbor, MI, USA \\ ${ }^{j}$ Veterans Affairs Center for Practice Management and Outcomes Research, Ann Arbor, MI, USA
}

\begin{abstract}
Background: Detection of "any cognitive impairment" is mandated as part of the Medicare annual wellness visit, but screening all patients may result in excessive false positives.

Methods: We developed and validated a brief Dementia Screening Indicator using data from four large, ongoing cohort studies (the Cardiovascular Health Study [CHS]; the Framingham Heart Study [FHS]; the Health and Retirement Study [HRS]; the Sacramento Area Latino Study on Aging [SALSA]) to help clinicians identify a subgroup of high-risk patients to target for cognitive screening. Results: The final Dementia Screening Indicator included age (1 point/year; ages, 65-79 years), less than 12 years of education ( 9 points), stroke ( 6 points), diabetes mellitus ( 3 points), body mass index less than $18.5 \mathrm{~kg} / \mathrm{m}^{2}$ (8 points), requiring assistance with money or medications (10 points), and depressive symptoms (6 points). Accuracy was good across the cohorts (Harrell's C statistic: CHS, 0.68; FHS, 0.77; HRS, 0.76; SALSA, 0.78).

Conclusions: The Dementia Screening Indicator is a simple tool that may be useful in primary care settings to identify high-risk patients to target for cognitive screening.

(C) 2014 The Alzheimer's Association. All rights reserved.

Keywords:

Dementia; Screening; Risk prediction modeling; Primary care
\end{abstract} 669.

\section{Introduction}

There are currently 5.2 million individuals with Alzheimer's disease and other dementias in the United States, including one in eight of those age 65 years or older [1];

*Corresponding author. Tel.: +415-221-4810 x.4221; Fax: +415-750-

E-mail address: Deborah.barnes@ucsf.edu however, $50 \%$ to $75 \%$ of these cases are undiagnosed $[2,3,4]$. Current U.S. Preventive Service Task Force guidelines, which were published in 2003, recommend screening only when cognitive impairment or deterioration is suspected $[5,6]$. However, many patients with dementia appear normal during clinical encounters and do not exhibit traditional signs or symptoms until they are screened. The 2010 Patient Protection and Affordable Care Act now requires providers to "detect any cognitive 
impairment" as part of the newly established annual wellness visit (AWV) for Medicare recipients, but no specific guidelines for achieving this new mandate were provided [7].

Primary care clinicians face numerous barriers to dementia diagnosis, including patient visit time constraints; complexities of diagnosis, reimbursement and follow-up; lack of an effective treatment; and concern about causing distress in patients and their families [4,8]. However, research published during the past decade suggests that early diagnosis of dementia has many potential benefits for clinicians, patients, and family members. These benefits include earlier initiation of dementia treatment, which may delay symptom progression in some patients [9]; better management of care for other medical issues [10], which could potentially reduce avoidable hospitalizations [11]; greater patient involvement with planning for their future care and modification of the home environment for their protection; and caregiver participation in support programs, which have been found to reduce burden and depression $[12,13]$.

To provide guidance regarding detection of cognitive impairment during the AWV, an Alzheimer's Association work group recently recommended that a brief cognitive screening be performed on all Medicare patients who show either signs or symptoms of cognitive impairment or do not have an informant available to confirm a lack of cognitive impairment [14]. A potential consequence of this approach, however, is that many low-risk patientsespecially younger Medicare patients-may be screened simply because they do not have an informant with them at the time of the AWV. This could take time away from other important clinical issues and could potentially result in large numbers of false-positive findings, unnecessary referrals for expensive follow-up testing, and needless worry to patients and families.

The objective of the current study was to develop and validate a brief Dementia Screening Indicator for use in primary care settings to help identify a subgroup of patients that does not have overt signs or symptoms of cognitive impairment but, based on other risk factors, has an increased risk of dementia and could be targeted for cognitive screening. Thus, our goal was to develop an easy-to-use clinical tool that uses information already available or easily obtainable in the primary care setting to stratify older patients into low- and high-risk groups, with the goal of targeting cognitive screening to the latter group.

\section{Methods}

\subsection{Brief overview and study cohorts}

This research was performed by four teams of investigators, who coordinated their efforts to develop and validate a common Dementia Screening Indicator. Each team was associated with a well-established, community- or population-based cohort study. The four studies consisted of the Cardiovascular Health Study (CHS; team, KY, DB, and AK), the Framingham Heart Study (FHS; team, SS, AB, and SP], the Health and Retirement Study (HRS; team: DW, KL, and RM], and the Sacramento Area Latino Study on Aging (SALSA; team: MH, AL, and JN). These studies were selected because they included individuals from diverse geographic and race/ethnic backgrounds, ascertained subjects for incident dementia, and evaluated a broad palette of potential risk markers.

For each study, a special data set was created for the secondary data analyses performed in this investigation. Data were not pooled across studies; rather, each team conducted its own analyses. Table 1 provides an overview of basic characteristics of the cohorts associated with the four studies. Although the studies have been active for many years, the information about data collection, eligibility, and sample size contained in the table is specific to the current investigation. Detailed descriptions of the design and methods of each study are available in the scientific literature for CHS [15], FHS [16,17], HRS [18], and SALSA [19]. Additional information about the studies is available online at study-specific websites (CHS [20], FHS [21], HRS [22], and SALSA [23]. All studies obtained written, informed consent from study participants. The CHS analyses also were approved by the Committee on Human Research at the University of California, San Francisco, and the Research \& Development Committee at the San Francisco Veterans Affairs Medical Center.

\subsection{Ascertainment of dementia}

Each study used different procedures to ascertain dementia prevalence and incidence, and the details are available elsewhere (CHS [24-26], FHS [27,28], HRS [29,30], SALSA [19]). However, the minimum requirements for dementia diagnosis across the four studies were (i) cognitive impairment in at least two domains that reflected a decline from prior levels and (ii) sufficient severity to affect daily function. In CHS, FHS, and SALSA, diagnoses were based on consensus committee review. In HRS, diagnoses were based on validated cut points on a brief cognitive battery $[29,30]$.

\subsection{Predictive factors}

We first developed a list of potential predictive factors (or predictors) that were available in all or most of the cohorts and that would be readily available or easily assessed in most primary care settings. Demographic factors included age, sex, and years of education. Medical history included stroke, diabetes, hypertension, and coronary heart disease. Depressive symptoms were assessed on the basis of individual items from the Center for Epidemiologic Studies Depression Scale [31] and current use of antidepressant medication. The Center for Epidemiologic Studies 
Table 1

Characteristics of the four cohorts used to develop and validate the dementia screening indicator*

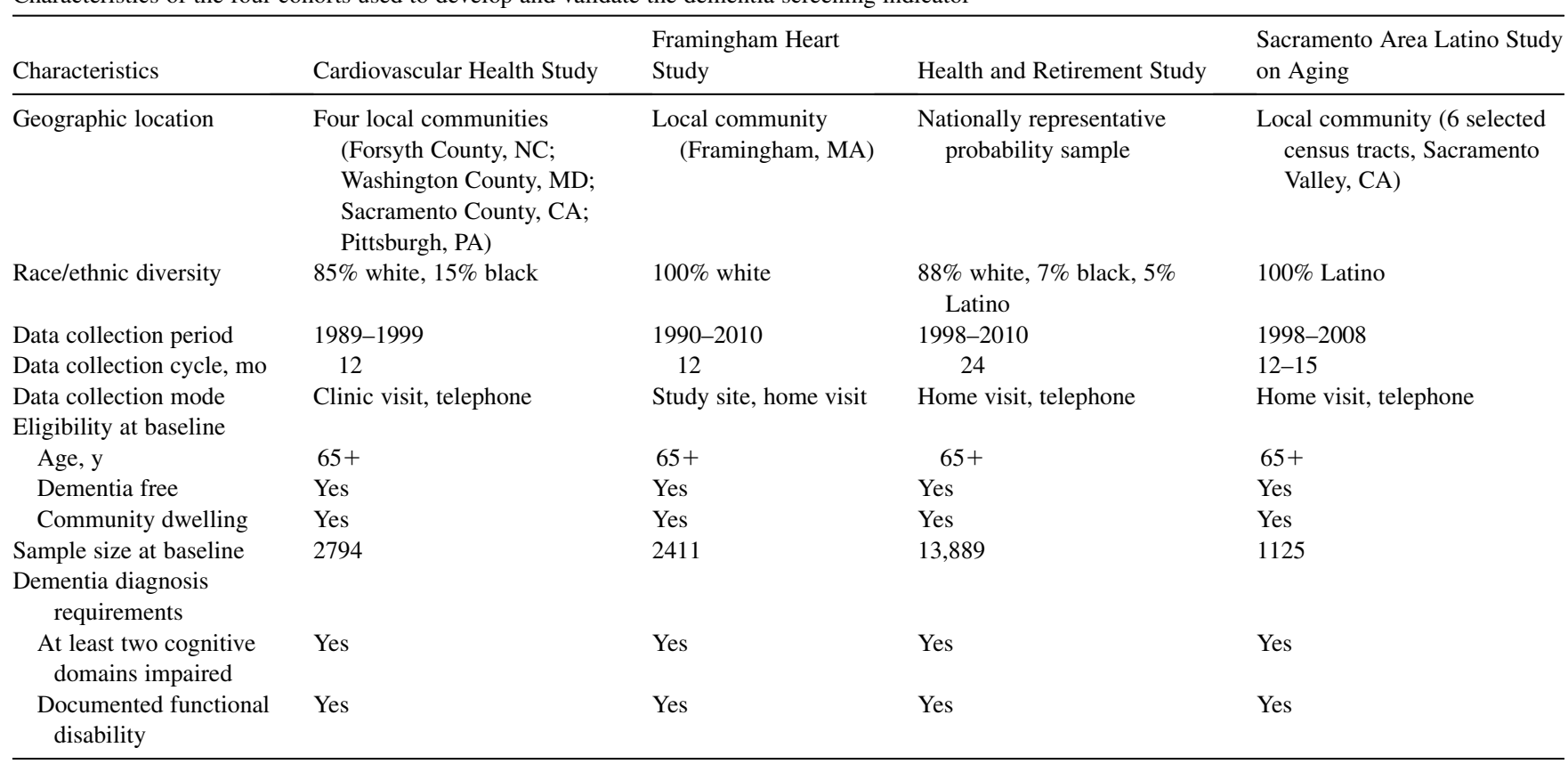

*Information pertains to current investigation. Age range restricted to 65 to 79 years at baseline.

Depression Scale items that were administered in all four cohorts were: I felt that everything I did was an effort, My sleep was restless, I could not "get going." Function was determined on the basis of self-report of difficulty with individual activities of daily living, instrumental activities of daily living, and mobility. Items common across the four cohorts included self-reported difficulty with eating, dressing, bathing, using the toilet, managing either money or managing medications, using the telephone, getting out of a bed or a chair, walking, climbing stairs, and performing heavy housework. Body mass index (BMI) was measured on the basis of weight in kilograms divided by height in square meters and was classified as underweight (BMI, <18.5), normal (BMI, 18.5-24.9), overweight (BMI, 25.0-29.9), or obese (BMI, 30 or greater).

\subsection{Analyses}

Knowing that the risk of dementia in the elderly increases with advancing age, we first used an empirical process to select an age at which the risk of dementia was considered high enough that routine screening for cognitive impairment should be considered on the basis of age alone. To accomplish this goal, we calculated 6-year Kaplan-Meier dementia incidence rates as a function of 5-year baseline age categories for each cohort (Table E1). Although dementia incidence rates varied widely across the studies, we observed a sharp increase in 6-year risk at age 80 years, with an approximate doubling of risk in persons age 80 to 84 years compared with those age 75 to 79 years, and absolute risks among persons 80 years or older that was more than one in four in all studies. Hence, we agreed collectively that risk was adequately high in all the studies that, at an age of 80 years or older, cognitive screening could be considered on the basis of age alone.

We then developed the Dementia Screening Indicator in 65- to 79-year-olds to determine which individuals in this younger age group had a risk of dementia similar to that observed in the older participants. We examined bivariate associations between predictor variables and 6-year incident dementia using $\chi^{2}$ tests for categorical variables and $t$ tests for continuous variables. Cox proportional hazards regression was then used to develop multivariable models of time to dementia onset, with subjects censored at death or the last evaluation. Each group determined independently which variables were most predictive of dementia incidence within their cohort. We then compared across the four cohorts to identify a subset of variables that were predictive consistently. When studies identified different variables that appeared to reflect similar domains, or asked similar questions in slightly different ways, we used an iterative group consensus process to harmonize variables across the studies. For example, some studies asked about difficulty managing money whereas others asked about difficulty managing medications, and all studies found that this "domain" was highly predictive of dementia risk. Therefore, our final model included the variable "difficulty managing money or medications." Each group then performed a final Cox regression analysis using the harmonized predictors, and a fixed-effects meta-analysis was performed to calculate the pooled hazard ratio estimates for each predictor across the four studies. Fixed-effects and random-effects approaches typically yield similar point estimates and differ mainly in their estimates of precision [32], which were not 
Table 2

Potential dementia predictors, by study cohort

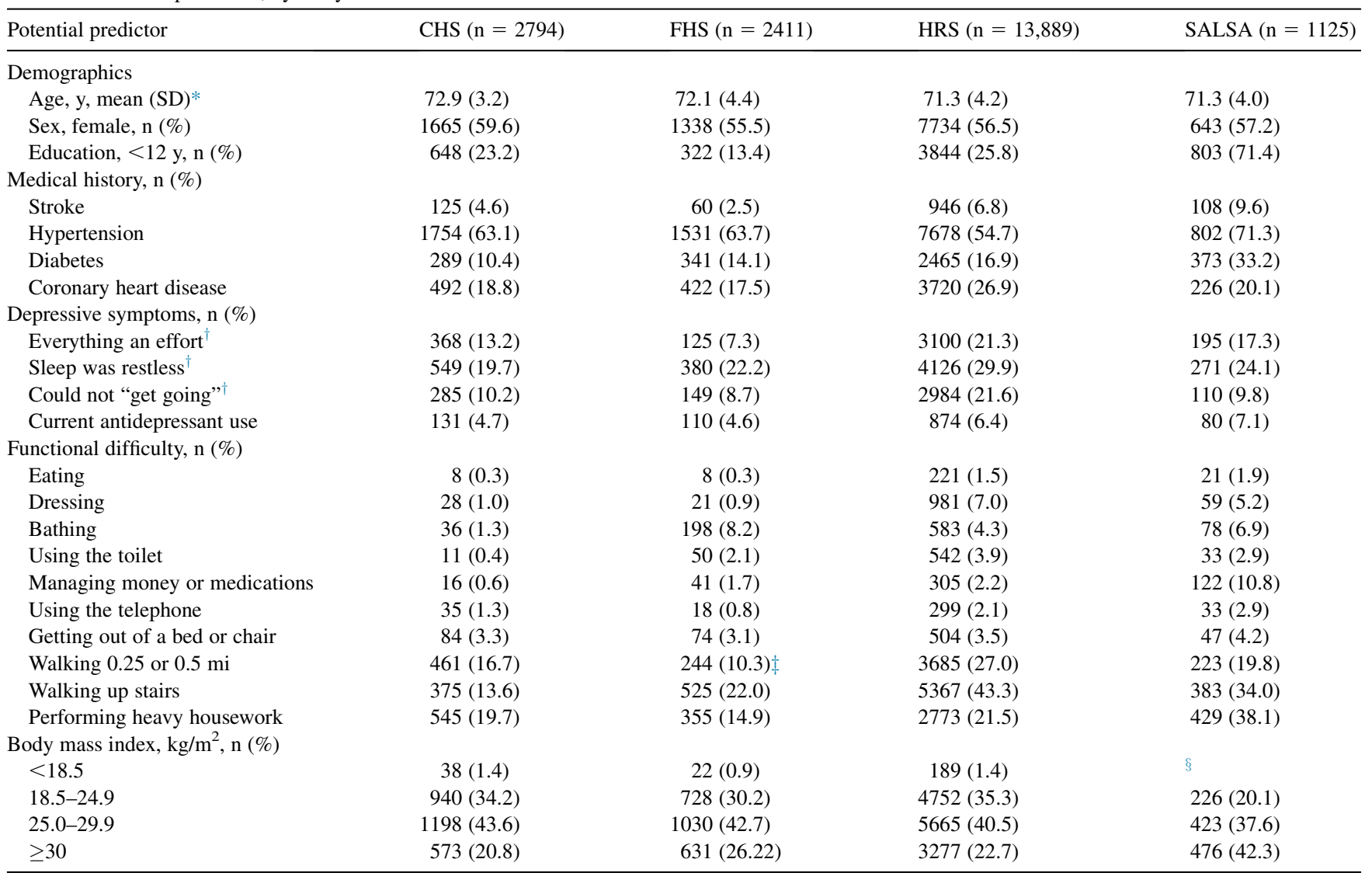

Abbreviations: CHS, Cardiovascular Health Study; FHS, the Framingham Heart Study; HRS, the Health and Retirement Study; SALSA, the Sacramento Area Latino Study on Aging; SD, standard deviation; BMI, body mass index.

NOTE. All values are number (percent) unless otherwise indicated. Numbers and percentages may not match as a result of missing data.

*All subjects are age 65 to 79 years.

${ }^{\dagger}$ Individual questions from the Center for Epidemiologic Studies Depression (CES-D) scale that were common to all studies, categorized as experiencing symptoms 3 days or more per week during the past week.

${ }^{\ddagger}$ Needs help walking 50 yards.

${ }^{\S}$ Participants included in the 18.5 -to-24.9 group as a result of small numbers.

needed for the current study. A point system was then created by dividing the $\beta$ coefficients for each variable in the final model by the $\beta$ coefficient for age and rounding to the nearest integer.

Discrimination of the final Dementia Screening Indicator using full model coefficients and the point system was assessed using Harrell's C statistic. In addition, sensitivity analyses were performed for CHS and HRS to assess discrimination within white, black, and Latino groups. Calibration of the final model was assessed by plotting actual risk as a function of decile of predicted risk for the four studies. Kaplan-Meier survival curves were calculated for each cohort using different risk score cut points to compare dementia incidence in low- and high-risk younger participants (65-79 years) with older participants (80-84 years). Several different cut points were examined, and the final cut point was chosen to provide the closest match between high-risk 65- to 79-year-olds and typical 80- to 84-year-olds across the four cohorts. Sensitivity and specificity values are not included because our tool is designed to identify a high-risk subgroup to consider for cognitive screening, rather than to detect dementia per se.

\section{Results}

Potential predictors and corresponding baseline cohort characteristics are presented in Table 2. The mean age ranged from 71 to 73 years, and the proportion of women was slightly greater than $50 \%$. Education levels varied widely, with less than 12 years of education reported in $13 \%$ of FHS participants vs. $71 \%$ of SALSA participants. Participants in SALSA also had greater percentages of obesity, based on BMI, and more comorbid medical conditions, including stroke, hypertension, and diabetes.

Although a slightly different constellation of factors was identified in each study as being predictive of dementia, the general domains identified were similar. The variables that were predictive consistently across the four studies 
Table 3

Predictors and corresponding hazard ratios for the final dementia risk calculator

\begin{tabular}{|c|c|c|c|c|c|c|}
\hline \multirow[b]{2}{*}{ Predictor } & \multicolumn{6}{|c|}{ Hazard ratio ( $95 \%$ confidence interval) } \\
\hline & CHS & FHS & HRS & SALSA & Combined & Points \\
\hline Age, y & $1.16(1.12-1.21)$ & $1.21(1.15-1.29)$ & $1.09(1.07-1.11)$ & $1.13(1.06-1.20)$ & 1.10 & Variable* \\
\hline Education, $<12$ y & $1.49(1.15-1.93)$ & $1.62(0.99-2.64)$ & $2.97(2.58-3.42)$ & $1.29(0.69-2.42)$ & 2.43 & 9 \\
\hline BMI, $<18.5 \mathrm{~kg} / \mathrm{m}^{2}$ & $2.66(1.37-5.18)$ & $6.26(2.51-15.61)$ & $1.82(1.25-2.64)$ & - & 2.25 & 8 \\
\hline Diabetes mellitus & $1.27(0.89-1.80)$ & $0.86(0.44-1.67)$ & $1.27(1.09-1.47)$ & $2.28(1.37-3.79)$ & 1.29 & 3 \\
\hline Stroke & $2.01(1.34-3.03)$ & $1.24(0.39-3.96)$ & $1.75(1.45-2.12)$ & $2.99(1.70-5.26)$ & 1.86 & 6 \\
\hline Needs help, money/medications & $1.90(0.70-5.12)$ & $2.56(1.01-6.46)$ & $2.76(2.29-3.33)$ & $1.93(1.07-3.47)$ & 2.65 & 10 \\
\hline Depressive symptoms ${ }^{\dagger}$ & $1.48(1.11-1.96)$ & $2.15(1.26-3.69)$ & $1.79(1.60-2.01)$ & $1.92(1.16-3.20)$ & 1.77 & 6 \\
\hline $\mathrm{C}$ statistic & $0.68(0.65-0.72)$ & $0.77(0.73-0.82)$ & $0.76(0.74-0.77)$ & $0.78(0.72-0.83)$ & & \\
\hline
\end{tabular}

Abbreviations: CHS, Cardiovascular Health Study; FHS, the Framingham Heart Study; HRS, the Health and Retirement Study; SALSA, the Sacramento Area Latino Study on Aging; BMI, body mass index.

*Points for age are determined as follows: 65 years, 0 point; 66-79 years, 1 point/year. For example, a 69-year-old patient would have 4 points.

†Current usage of antidepressants or reporting that "everything was an effort" for 3 days or more a week for the past week.

and were retained in the final model included older age, fewer years of education, history of stroke, presence of diabetes mellitus, low BMI, assistance needed with money or medications, and a composite depressive symptom variable (current usage of antidepressant medication or reporting that "everything was an effort" for 3 or more days per week during the past week; Table 3).

Discrimination of the final model based on Harrell's C statistic (95\% confidence interval) was good for each study (Table 3): CHS, 0.68 (0.65-0.72); FHS, 0.77 (0.73-0.82); HRS, $0.76 \quad(0.74-0.77) ; \quad$ SALSA, $0.78 \quad(0.72-0.83)$. Sensitivity analyses within CHS and HRS also suggested that discrimination was good within different race/ethnic groups-CHS: whites, $0.70(0.66-0.73)$; blacks, 0.65 (0.58-0.72); HRS: whites, 0.75 (0.73-0.77); blacks, 0.70 (0.68-0.72); Latinos, $0.71(0.67-0.75)$. Calibration of the final model suggested good correspondence between predicted and actual risk over deciles of predicted risk, particularly for the greatest deciles (Fig. E1).

Table 3 also shows the hazard ratios for each final predictor within the four studies as well as the combined hazard ratio and number of points assigned for each factor. Age was assigned 0 point at age 65 years and 1 point per year for ages 66 to 79 years. Therefore, the point values for the other predictors can be interpreted as the increased risk associated with being older by that number of years. For example, a person with a history of stroke (6 points) would have an average dementia risk equivalent to someone without a history of stroke who was 6 years older. The point values for the other factors were as follows: fewer than 12 years of education, 9 points; BMI less than $18.5,8$ points; diabetes, 3 points; needing help with money or medications, 10 points; and depressive symptoms, 6 points. Therefore, the Dementia Screening Indicator score may range from 0 points (age 65 years, no other predictors present) to 56 points (age 79 years, all other predictors present).

A cut point of 22 points or more on the Dementia Screening Indicator enabled stratification of 65- to 79 -year-olds into high-risk and low-risk groups (Fig 1). Dementia incidence in high-risk 65 - to 79-year-olds was comparable with dementia incidence in the general population of 80- to 84-year-olds in all four cohorts. The percentages of 65- to 79-year-olds whose scores were 22 points or more and who would, therefore, be recommended for cognitive screening were $8.2 \%$ in CHS, $6.0 \%$ in FHS, $11.2 \%$ in HRS, and $26.7 \%$ in SALSA.

A Web-based version of the Dementia Screening Indicator is available [33].

\section{Discussion}

We developed and validated a simple Dementia Screening Indicator that was designed specifically for primary care settings to help clinicians identify a subgroup of older patients with an increased risk of dementia who could be targeted for cognitive screening. The Dementia Screening Indicator includes seven simple items-age, educational attainment, history of stroke, presence of diabetes mellitus, difficulty managing money or medications, low BMI, and depressive symptoms-that are combined to create a point score, with greater scores indicating greater risk of developing dementia. Dementia Screening Indicator scores or 22 points or more identified 65- to 79-year-olds whose 6-year dementia risk was comparable with 80 - to 84 -year-olds in all four cohorts. Furthermore, the percentage of subjects identified as high risk based on this score was relatively low, ranging from $6 \%$ in FHS to $27 \%$ in SALSA, suggesting that usage of this tool in clinical settings could potentially improve efficiency by targeting cognitive screening to a small, high-risk subgroup.

The accuracy of the Dementia Screening Indicator was consistently good across four large community- or population-based cohort studies with wide-ranging demographic and race/ethnic characteristics, suggesting broad generalizability. C statistics ranged from 0.68 to 0.78 , which is consistent with other widely used clinical risk indices such as the Framingham Heart Index [34] and the Breast Cancer Risk Assessment Tool [35].

Several other dementia risk prediction tools have been developed during the past few years [36-44]. However, none are ideal for primary care or the AWV because 


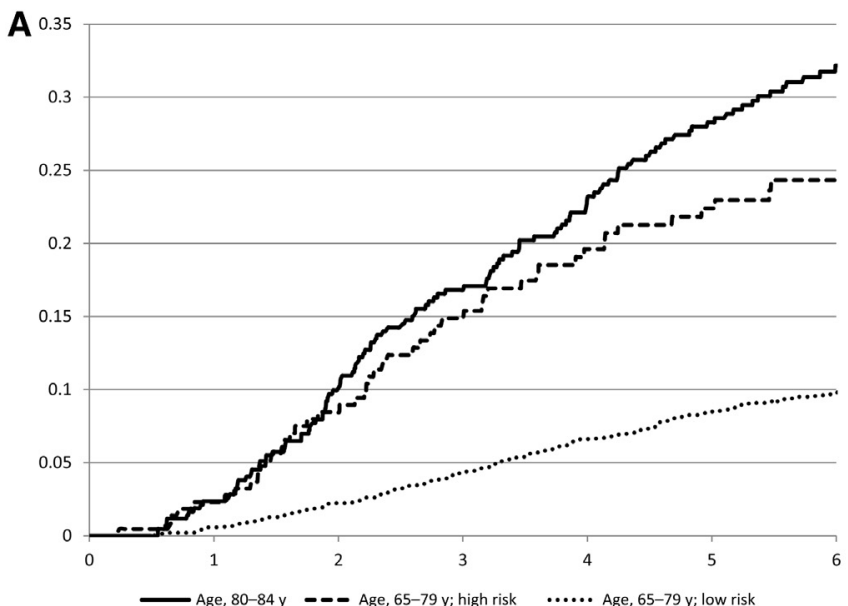

C

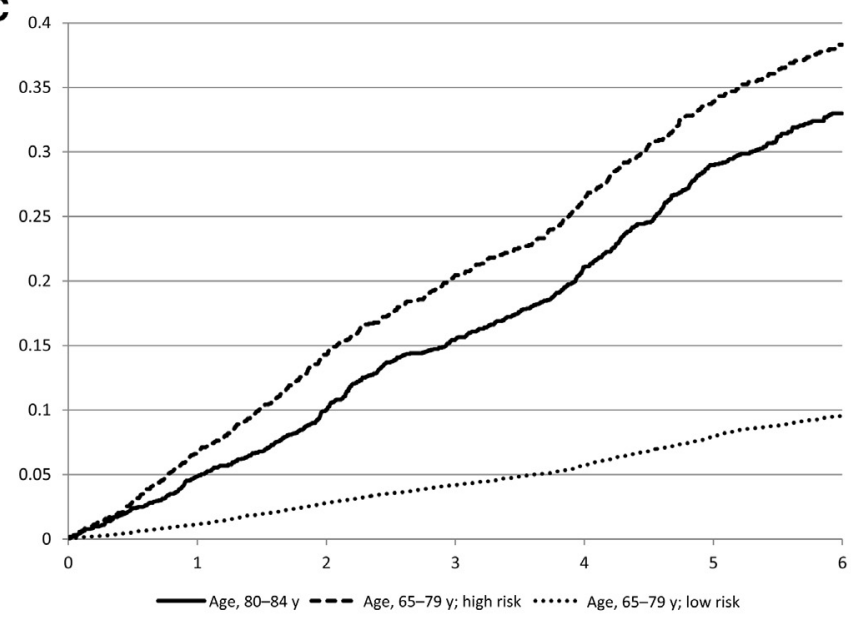

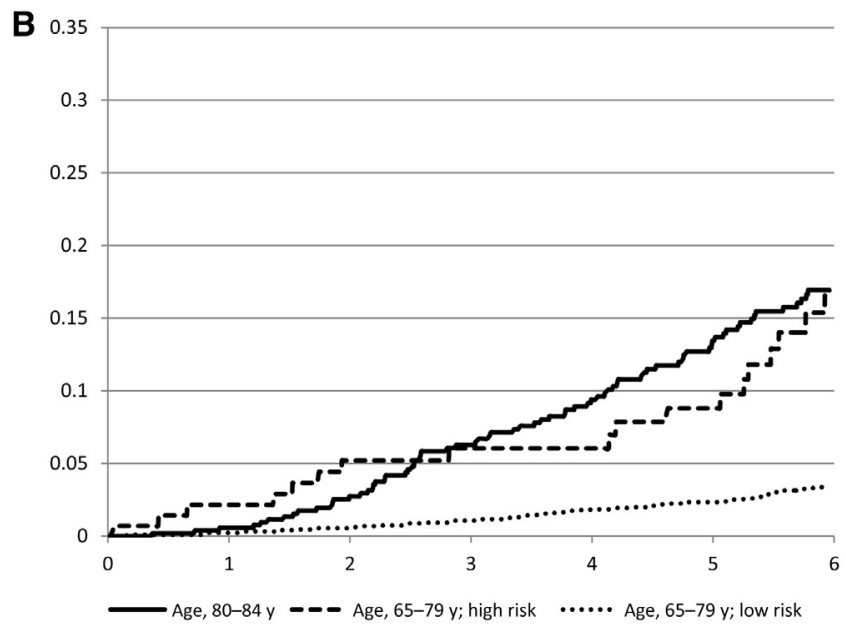

D

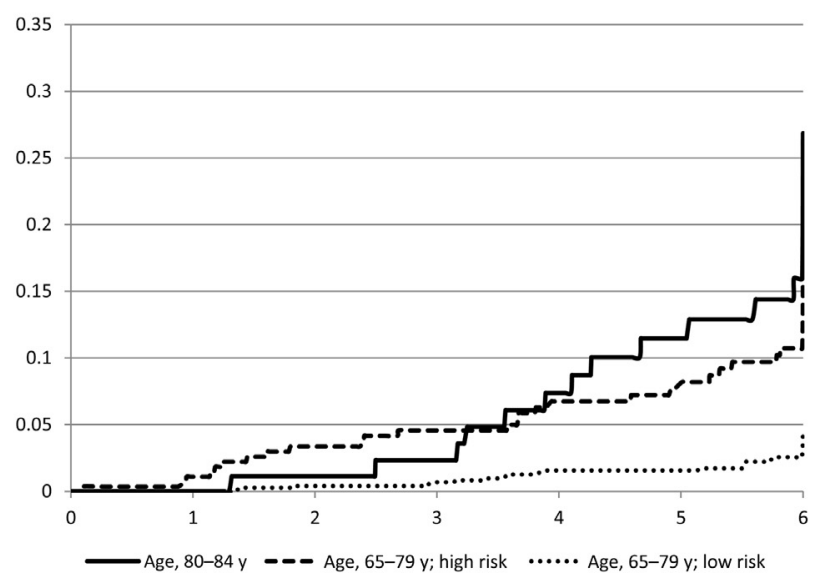

Fig. 1. (A-D) Six-year dementia incidence by age and dementia risk group. The y-axis indicates the proportion of study participants that developed dementia. The $\mathrm{x}$-axis indicates dementia incidence over six years in 65- to 79-year-olds with low dementia risk scores ( $<22$ points, dotted lines), 65- to 79-year-olds with high dementia risk scores ( $\geq 22$ points, dashed lines), and normal-risk 80- to 84-year-olds (solid lines) in the Cardiovascular Health Study (A), the Framingham Heart Study (B), the Health and Retirement Study (C), and the Sacramento Area Latino Study on Aging (D). All figures show good separation between the lowrisk and high-risk groups, with comparable dementia incidence in high-risk 65- to 79-year-olds and normal-risk 80- to 84-year-olds.

they consider either a restricted range of risk factors (e.g., midlife only [41], vascular only [42,43], general health questions only [44]) or include measures of cognitive function [37-40], or other tests that are expensive or require special equipment [37]. The goal of the current study was to provide a tool that can be used easily in primary care settings to identify a subset of patients with an increased dementia risk who could then be targeted for screening with a standard cognitive instrument.

Although the Patient Protection and Affordable Care Act now requires detection of "any cognitive impairment" during the AWV [7], screening all older adults for cognitive impairment is not currently recommended by the U.S. Preventive Services Task Force [6]. This conclusion was based on lack of evidence for clinical benefit as well as concern regarding potential harms associated with false-positive findings that could result in costly follow-up testing and unnecessary patient worry. However, these guidelines were published a decade ago, and there is now a growing body of research suggesting that timely diagnosis of dementia has many potential benefits for clinicians, patients, and family members. Earlier diagnosis enables earlier initiation of treatment, which delays worsening of symptoms in some patients [9]. In addition, knowledge that a patient has dementia may enable clinicians to manage care more effectively for other medical issues by simplifying medication regimens, providing written directions, and increasing involvement of family members and other mechanisms of social support [10]. This, in turn, may lead to the prevention of avoidable hospitalizations [11]. Early detection of cognitive impairment may also benefit patients by enabling them to be involved with decision making related to their future care, by prompting alterations in the home environment to increase safety, and by enabling them to participate in research studies if they wish. Last, early detection of cognitive impairment can benefit caregivers by providing them with an opportunity to participate in support programs, which have been found to reduce caregiver burden and depression $[12,13]$. 


\begin{tabular}{|c|c|c|c|}
\hline \multicolumn{4}{|c|}{$\begin{array}{l}\text { Do you think your patient may have cognitive impairment based on: } \\
\qquad \text { your observations } \quad \square \text { concerns of patient } \quad \square \text { concerns of family or others } \\
\text { If yes to any: Your patient should be screened for cognitive impairment. }\end{array}$} \\
\hline \multicolumn{4}{|l|}{$\begin{array}{l}\text { Is your patient age } 80 \text { years or older? } \quad \square \text { yes } \quad \square \text { no } \\
\text { If yes: Your patient should be screened for cognitive impairment. } \\
\text { If no: Administer Dementia Screening Indicator. }\end{array}$} \\
\hline \multicolumn{3}{|l|}{ Dementia Screening Indicator } & Points \\
\hline \multicolumn{4}{|c|}{$\begin{array}{l}\text { 1. How old is your patient? __ years } \\
\text { If 65-79 years, assign } 1 \text { point per year above age 65. Example: age } 65 \text { years receives } 0 \text { points; } \\
\text { age } 72 \text { years receives } 7 \text { points. }\end{array}$} \\
\hline 2. Does your patient have $<12$ years of education? ${ }^{1}$ & No $(0)$ & Yes (9) & \\
\hline 3. Is your patient's BMI $<18.5 \mathrm{~kg} / \mathrm{m}^{2} ?^{2}$ & No $(0)$ & Yes $(8)$ & \\
\hline 4. Does your patient have a history of type 2 diabetes? & No $(0)$ & Yes (3) & \\
\hline 5. Has your patient ever had a stroke? & No $(0)$ & Yes (6) & \\
\hline $\begin{array}{l}\text { 6. Does your patient need help from others to manage money or } \\
\text { medications? }\end{array}$ & No $(0)$ & Yes $(10)$ & \\
\hline $\begin{array}{l}\text { 7. Does your patient currently take anti-depressant medications OR report } \\
\text { that "everything was an effort" } \geq 3 \text { days per week over the past week? }\end{array}$ & No $(0)$ & Yes (6) & \\
\hline 22, your patient should be screened for cognitive & & & \\
\hline
\end{tabular}

\footnotetext{
${ }^{1}$ Did not graduate from high school or pass a General Educational Development (GED) Test

${ }^{2}$ http://nhlbisupport.com/bmi/

${ }^{3}$ Ask your patient and/or family member if present: Do you need help from others to manage money or medications?

${ }^{4}$ Ask your patient: In the past week, how many days did you feel that everything was an effort?

$\square$ rarely (<1 day) $\square$ little (1-2 days) $\square$ moderate (3-4 days) $\square \operatorname{most}(5-7$ days)

If the answer is either "moderate" or "most," then item 7 in the Dementia Screening Indicator receives a score of 6 points.
}

Fig. 2. Decisional flow chart regarding screening for cognitive impairment in the primary care setting.

On the basis of empirical considerations, we determined that routine cognitive screening should be considered for all older adults beginning at age 80 years. We recognize that not all will agree with this conclusion. However, in our view, the potential benefits of routine screening likely outweigh the potential harms, given the high incidence of dementia in this age group.
Fig. 2 provides a decisional flow chart to guide clinicians regarding when to screen for cognitive impairment in the primary care setting. Screening is always indicated if cognitive impairment is suspected on the basis of clinical observation, patient concern, or family concern. In addition, as noted earlier, we recommend screening for all patients age 80 years 
or older. In patients age 65 to 79 years, the Dementia Screening Indicator provides a simple tool to help clinicians discriminate between those patients with a high risk vs. a low risk of developing dementia within 6 years, so that screening can be targeted toward those with higher risk. Our findings suggest that patients who receive a score of 22 points or greater on the Dementia Screening Indicator have an elevated risk of developing dementia and should be considered for screening, although individual clinicians may choose to be more or less aggressive.

Our approach builds on recommendations for assessment of cognitive impairment during the AWV developed recently by an Alzheimer's Association work group [14]. These recommendations call for brief cognitive screening in all older patients who $(i)$ show signs or symptoms of cognitive impairment on the basis of clinician observation, patient selfreport, or informant report; or (ii) do not have an informant available to provide information on signs and symptoms. These guidelines also include a list of cognitive screening tools that are well suited for the primary care setting. Patients who screen positive are then referred for a full dementia evaluation. The Dementia Screening Indicator provides a complementary approach in which patients, with or without an informant, would be screened only if they had signs or symptoms or were identified as high risk based on either age of 80 years or more, or scoring 22 points or more on the Dementia Screening Indicator.

The predictors included in the Dementia Screening Indicator have all been identified previously as being associated with increased dementia risk in prior studies [45-50]. However, these predictors are not necessarily associated causally with increased dementia risk. In fact, several predictors may be markers of preclinical or early-stage disease in some individuals, rather than true risk factors. Requiring assistance with money or medications [51], low BMI [52], and depression [53] all may occur during the preclinical period. In addition, low educational attainment is likely to be a proxy for a wide range of factors that could potentially increase dementia risk by lowering cognitive reserve [54]. Therefore, changes in these predictors will not necessarily lead to changes in risk. Nonetheless, the combination of the seven items included in the Dementia Screening Indicator were predictive across four large, diverse cohorts, suggesting they are consistent markers of increased dementia risk, even if the etiology of the association is not clear.

\subsection{Strengths and limitations}

A key strength of this study is that the Dementia Screening Indicator was developed and validated using data from four well-characterized, community- or population-based cohort studies that are generally reflective of the U.S. population. Despite a diversity of approaches to measuring the identified risk factors, accuracy remained consistent across the four studies, suggesting the tool would retain its validity regardless of the method used to measure the risk factors. Accuracy was somewhat lower in CHS than the other cohorts, which may reflect the older age of the data (follow-up ended in 1999) or the retrospective nature of the dementia adjudication process [25]. In addition, a greater percentage of participants in SALSA were classified as high risk. This may reflect the lower educational attainment in this group.

Our study also has limitations. First, we were unable to consider some potentially important predictors because they were not collected routinely in all the studies. One example is physical inactivity, which may contribute to as many as one in five dementia cases in the United States [55]. In addition, our tool was not validated externally, and several race/ethnic groups were not represented in the current study, including Asians, Native Americans, and Pacific Islanders. It would be useful to validate the Dementia Screening Indicator in other study populations in future studies. Additional studies also are needed to assess the feasibility of using the Dementia Screening Indicator in clinical settings and to determine whether it increases the efficiency of dementia detection or improves patient outcomes.

\section{Conclusion}

The Dementia Screening Indicator is a simple tool designed for use by primary care clinicians to identify high-risk older patients who could be targeted for cognitive screening. Restricting cognitive screening to patients identified as high risk by the Dementia Screening Indicator, as opposed to screening all patients, may enable clinicians to maximize the potential benefits of screening while minimizing potential harms.

\section{Acknowledgments}

We thank Lewis H. Kuller and Oscar L. Lopez from the Cardiovascular Health Study (CHS) and Philip A. Wolf and Rhoda Au from the Framingham Heart Study (FHS). We especially thank Dallas W. Anderson, Jonathan W. King, Nina B. Silverberg, Molly V. Wagster, and the National Institute on Aging for their facilitation of the project. This study was funded by the National Institute on Aging, through various grants. K. Yaffe, D. E. Barnes, and A. Koyama, representing the Cardiovascular Health Study, were supported in part by K24-AG031155 (principle investigator, KY). The CHS was supported by contracts HHSN268201200036 C, N01HC85239, N01 HC55222, N01HC85079, N01HC 85080, N01HC85081, N01HC85082, N01HC85083, and N01HC85086, and grant HL080295 from the National Heart, Lung, and Blood Institute, with additional contribution from the National Institute of Neurological Disorders and Stroke. Additional support was provided by AG023629 from the National Institute on Aging. A full list of principal CHS investigators and institutions can be found at http://www.chsnhlbi.org/PI.htm. D. E. Barnes was also supported in part by the S.D. Bechtel, Jr. Foundation. S. Seshadri, A. S. Beiser, and S. R. Preis, representing the FHS, were supported in 
part by N01-HC-25195, AG081220, AG033193, AG033040, AG013846, and NS017950. D. R. Weir, K. M. Langa, and R. J. McCammon, representing the Health and Retirement Study, were supported in part by U01 AG009740. Last, M. N. Haan, A. Lee, and J. Neuhaus, representing the Sacramento Area Latino Study on Aging, were supported in part by AG12975 and DK60753. The National Institute on Aging recognized the need for this research initially, established guidelines about desirable properties of a dementia screening indicator, invited the four research teams to participate, encouraged their cooperation, and monitored their progress. Final decisions regarding the content of the manuscript and the decision to publish were made by the authors.

\section{RESEARCH IN CONTEXT}

1. Systematic review: We searched PUBMED using $d e$ mentia as a major subject heading term and the words risk and prediction, risk index, risk score, and prognostic index, with results restricted to Englishlanguage studies performed in humans age 65 years or older. A total of 181 references were retrieved, and the titles and abstracts were reviewed. None of the articles identified provided a simple clinical tool that did not include cognitive items and could be used in primary care settings to identify older adults with an increased risk of dementia.

2. Interpretation: The Dementia Screening Indicator fills an important gap in the field by providing primary care clinicians with a simple tool to help identify a subset of older patients without overt signs or symptoms who have an elevated risk of dementia and could be targeted for cognitive screening. Restricting cognitive screening to high-risk patients, as opposed to screening all patients, may enable clinicians to maximize the potential benefits of screening while minimizing potential harms.

3. Future Directions: Additional studies are needed to examine the feasibility of using the Dementia Screening Indicator in clinical settings and to determine whether it increases the efficiency of dementia detection or improves patient outcomes.

\section{References}

[1] Thies W, Bleiler L, Alzheimer's Association. 2013 Alzheimer's disease facts and figures. Alzheimers Dement 2013;9:208-45.

[2] Boise L, Neal MB, Kaye J. Dementia assessment in primary care: results from a study in three managed care systems. J Gerontol A Biol Sci Medical Sci 2004;59:M621-6.
[3] Callahan CM, Hendrie HC, Tierney WM. Documentation and evaluation of cognitive impairment in elderly primary care patients. Ann Intern Med 1995;122:422-9.

[4] Ganguli M, Rodriguez E, Mulsant B, Richards S, Pandav R, Bilt JV, et al. Detection and management of cognitive impairment in primary care: the Steel Valley Seniors Survey. J Am Geriatr Soc 2004;52:1668-75.

[5] Boustani M, Peterson B, Hanson L, Harris R, Lohr KN, US Preventive Services Task Force. Screening for dementia in primary care: a summary of the evidence for the U.S. Preventive Services Task Force. Ann Intern Med 2003;138:927-37.

[6] US Preventive Services Task Force. Screening for dementia: recommendation and rationale. Ann Intern Med 2003;138:925-6.

[7] Office of the Federal Register and the Government Printing Office. 410.15 Annual wellness visits providing personalized prevention plan services: conditions for and limitations on coverage. [Accessed 2013 February 19]. Available from: http://www.ecfr.gov/cgi-bin/ text-idx? $=$ ecfr\&sid $=6 \mathrm{~b} 50669 \mathrm{da} 0 \mathrm{f} 96 \mathrm{db} 4 \mathrm{eea} 346533 \mathrm{db} 23747 \& \mathrm{rgn}=\mathrm{div}$ $8 \&$ view $=$ text $\&$ node $=42: 2 \cdot 0 \cdot 1 \cdot 2 \cdot 10.2 .35 .4 \&$ idno $=42$.

[8] Hinton L, Franz CE, Reddy G, Flores Y, Kravitz RL, Barker JC. Practice constraints, behavioral problems, and dementia care: primary care physicians' perspectives. J Gen Intern Med 2007; 22:1487-92.

[9] Hogan DB, Bailey P, Black S, Carswell A, Chertkow H, Clarke B, et al. Diagnosis and treatment of dementia: 4. Approach to management of mild to moderate dementia. Can Med Assoc J 2008; 179:787-93.

[10] Okura T, Heisler M, Langa KM. Association between cognitive function and social support with glycemic control in adults with diabetes mellitus. J Am Geriatr Soc 2009;57:1816-24.

[11] Lin PJ, Fillit HM, Cohen JT, Neumann PJ. Potentially avoidable hospitalizations among Medicare beneficiaries with Alzheimer's disease and related disorders. Alzheimers Dement 2013;9:30-8.

[12] Health Quality, Ontario. Caregiver- and patient-directed interventions for dementia: an evidence-based analysis: Ont Health Technol Assessment Ser. 2008;8:1-98.

[13] Parker D, Mills S, Abbey J. Effectiveness of interventions that assist caregivers to support people with dementia living in the community: a systematic review. Int J Evidence-Based Healthcare 2008;6:137-72.

[14] Cordell CB, Borson S, Boustani M, Chodosh J, Reuben D, Verghese J, et al. Alzheimer's Association recommendations for operationalizing the detection of cognitive impairment during the Medicare annual wellness visit in a primary care setting. Alzheimer Dement 2012;9:141-50.

[15] Fried LP, Borhani NO, Enright P, Furberg CD, Gardin JD, Kronmal JA, et al. The Cardiovascular Health Study: design and rationale. Ann Epidemiol 1991;1:263-76.

[16] Dawber TR, Kannel WB. The Framingham Study: an epidemiological approach to coronary heart disease. Circulation 1966;34:553-5.

[17] Feinleib M, Kannel WB, Garrison RJ, McNamara PM, Castelli WP. The Framingham Offspring Study: design and preliminary data. Prevent Med 1975;4:518-25.

[18] National Institute on Aging. Growing older in America: the Health and Retirement Study. Washington, DC: US Department of Health and Human Services; 2007.

[19] Haan MN, Mungas DM, Gonzalez HM, Ortiz TA, Acharya A, Jagust WJ. Prevalence of dementia in older Latinos: the influence of type 2 diabetes mellitus, stroke and genetic factors. J Am Geriatr Soc 2003;51:169-77.

[20] CHS Coordinating Center. CHS-NHLBI: The Cardiovascular Health Study. Available at: http://www.chs-nhlbi.org/default.htm. Accessed January 21, 2014.

[21] Framingham Heart Study. A project of the National Heart, Lung, and Blood Institute and Boston University. Available at: http://www. framinghamheartstudy.org/. Accessed January 21, 2014.

[22] The Regents of the University of Michigan. Health and Retirement Study. Available at: http://hrsonline.isr.umich.edu/. Accessed January 21, 2014. 
[23] National Archive of Computerized Data on Aging. Sacramento Latino Study on Aging (SALSA Study). Available at: http://www.icpsr.umich. edu/icpsrweb/NACDA/studies/29323. Accessed January 21, 2014.

[24] Fitzpatrick AL, Kuller LH, Ives DG, Lopez OL, Jagust W, Breitner JC, et al. Incidence and prevalence of dementia in the Cardiovascular Health Study. J Am Geriatr Soc 2004;52:195-204.

[25] Kuller LH, Lopez OL, Newman A, et al. Risk factors for dementia in the cardiovascular health cognition study. Neuroepidemiology 2003; 22:13-22.

[26] Lopez OL, Kuller LH, Fitzpatrick A, Ives D, Becker JT, Beauchamp N. Evaluation of dementia in the cardiovascular health cognition study. Neuroepidemiology 2003;22:1-12.

[27] Seshadri S, Fitzpatrick AL, Ikram MA, et al. Genome-wide analysis of genetic loci associated with Alzheimer disease. JAMA 2010; 303:1832-40.

[28] Seshadri S, Wolf PA, Beiser A, et al. Lifetime risk of dementia and Alzheimer's disease: the impact of mortality on risk estimates in the Framingham Study. Neurology 1997;49:1498-504.

[29] Crimmins EM, Kim JK, Langa KM, Weir DR. Assessment of cognition using surveys and neuropsychological assessment: the Health and Retirement Study and the Aging, Demographics, and Memory Study. J Gerontol B Psychol Sci Social Sci 2011;66:i162-71.

[30] Langa KM, Plassman BL, Wallace RB, Herzog AR, Heeringa SG, Ofstedal MB, et al. The Aging, Demographics, and Memory Study: study design and methods. Neuroepidemiology 2005;25:181-91.

[31] Radloff LS. The CES-D scale: a self report depression scale for research in the general population. Appl Psychol Med 1977;1:385-401.

[32] Schmidt FL, Oh IS, Hayes TL. Fixed- versus random-effects models in meta-analysis: model properties and an empirical comparison of differences in results. Br J Math Statistical Psychol 2009;62:97-128.

[33] Dementia Screening Indicator. Available at: http://campuslifeservices. ucsf.edu/clsforms/documentsmedia/dementiarisk/. Accessed January $21,2014$.

[34] Kannel WB, McGee D, Gordon T. A general cardiovascular risk profile: the Framingham Study. Am J Cardiol 1976;38:46-51.

[35] Gail MH, Brinton LA, Byar DP, Corle DK, Green SB, Schairer c, et al. Projecting individualized probabilities of developing breast cancer for white females who are being examined annually. J Natl Cancer Institute 1989;81:1879-86.

[36] Stephan BC, Kurth T, Matthews FE, Brayne C, Dufouil C. Dementia risk prediction in the population: are screening models accurate? Nat Rev Neurol 2010;6:318-26.

[37] Barnes DE, Covinsky KE, Whitmer RA, Kuller LH, Lopez OL, Yaffe K. Predicting risk of dementia in older adults: the late-life dementia risk index. Neurology 2009;73:173-9.

[38] Barnes DE, Covinsky KE, Whitmer RA, Kuller LH, Lopez OL, Yaffe K. Commentary on "Developing a national strategy to prevent dementia: Leon Thal Symposium 2009.” Dementia risk indices: a framework for identifying individuals with a high dementia risk. Alzheimer Dement 2010;6:138-41.

[39] Chary E, Amieva H, Peres K, Orgogozo JM, Dartigues JF, JacqminGadda H. Short- versus long-term prediction of dementia among subjects with low and high educational levels. Alzheimers Dement 2012;9:562-71.

[40] Jessen F, Wiese B, Bickel H, Eifflander-Gorfer S, Fuchs A, Kaduszkiewicz H, et al. Prediction of dementia in primary care patients. PLoS One 2011;6:e16852.

[41] Kivipelto M, Ngandu T, Laatikainen T, Winblad B, Soininen H, Tuomilehto J. Risk score for the prediction of dementia risk in 20 years among middle aged people: a longitudinal, population-based study. Lancet Neurol 2006;5:735-41.

[42] Mitnitski A, Skoog I, Song X, Waern M, Ostling S, Sundh V, et al. A vascular risk factor index in relation to mortality and incident dementia. Eur J Neurology 2006;13:514-21.

[43] Reitz C, Tang MX, Schupf N, Manly JJ, Mayeux R, Luchsinger JA. A summary risk score for the prediction of Alzheimer disease in elderly persons. Arch Neurol 2010;67:835-41.

[44] Song X, Mitnitski A, Rockwood K. Nontraditional risk factors combine to predict Alzheimer disease and dementia. Neurology 2011;77:227-34.

[45] Ziegler-Graham K, Brookmeyer R, Johnson E, Arrighi HM. Worldwide variation in the doubling time of Alzheimer's disease incidence rates. Alzheimers Dement 2008;4:316-23.

[46] Caamano-Isorna F, Corral M, Montes-Martinez A, Takkouche B. Education and dementia: a meta-analytic study. Neuroepidemiology 2006;26:226-32.

[47] Lu FP, Lin KP, Kuo HK. Diabetes and the risk of multi-system aging phenotypes: a systematic review and meta-analysis. PLoS One 2009; 4:e4144.

[48] Ownby RL, Crocco E, Acevedo A, John V, Loewenstein D. Depression and risk for Alzheimer disease: systematic review, meta-analysis, and metaregression analysis. Arch Gen Psychiatry 2006;63:530-8.

[49] Ivan CS, Seshadri S, Beiser A, Au R, Kase CS, Kelly-Hayes M, et al. Dementia after stroke: the Framingham Study. Stroke 2004; $35: 1264-8$.

[50] Fitzpatrick AL, Kuller LH, Lopez OL, Diehr P, O’Meara ES, Longstreth WT Jr, et al. Midlife and late-life obesity and the risk of dementia: Cardiovascular Health Study. Arch Neurol 2009; 66:336-42.

[51] Barberger-Gateau P, Fabrigoule C, Helmer C, Rouch I, Dartigues JF. Functional impairment in instrumental activities of daily living: an early clinical sign of dementia? J Am Geriatr Soc 1999;47:456-62.

[52] Ogunniyi A, Gao S, Unverzagt FW, Baiyewu O, Gureje O, Nguyen JT, et al. Weight loss and incident dementia in elderly Yoruba Nigerians: a 10-year follow-up study. Int Psychogeriatr 2011;23:387-94.

[53] Barnes DE, Alexopoulos GS, Lopez OL, Williamson JD, Yaffe K. Depressive symptoms, vascular disease, and mild cognitive impairment: findings from the Cardiovascular Health Study. Arch Gen Psychiatry 2006;63:273-9.

[54] Stern Y. Cognitive reserve in ageing and Alzheimer's disease. Lancet Neurol 2012;11:1006-12.

[55] Barnes DE, Yaffe K. The projected effect of risk factor reduction on Alzheimer's disease prevalence. Lancet Neurol 2011;10:819-28. 


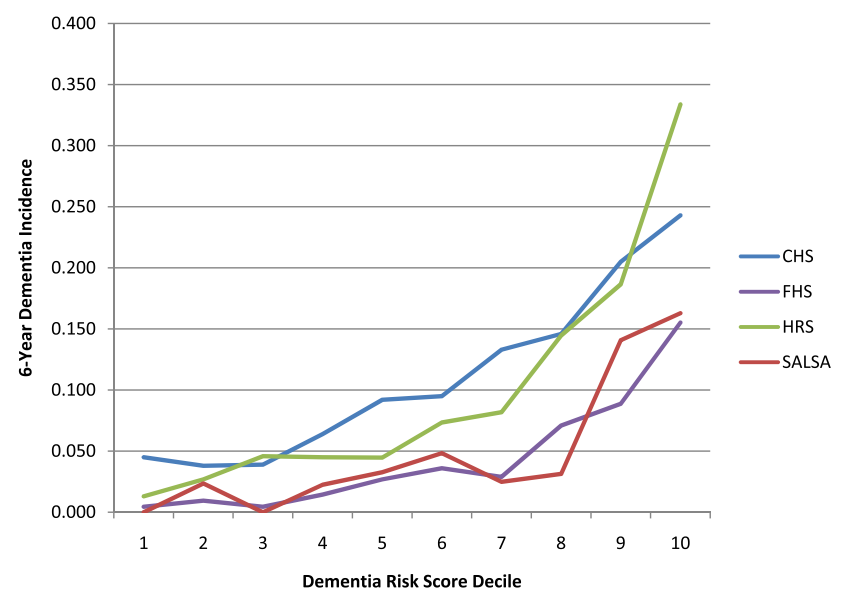

Fig. E1. Calibration of dementia screening indicator scores across the cohorts. Calibration of the final model was assessed by plotting actual dementia risk as a function of predicted risk decile for the four studies, which suggested reasonable correspondence between predicted and actual risk, particularly for the higher deciles.

Table E1

Six-year dementia incidence for each study population

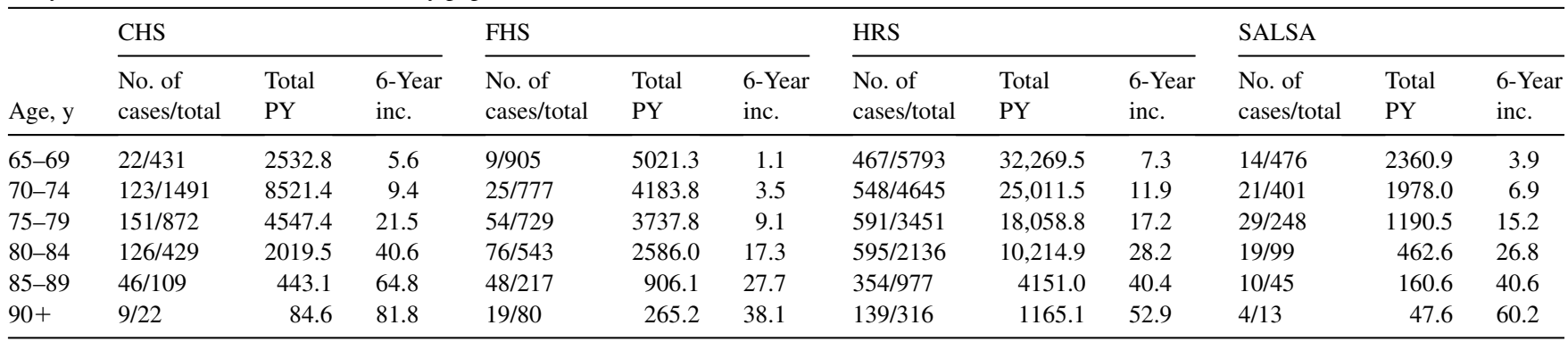

Abbreviations: CHS, Cardiovascular Health Study; FHS, Framingham Heart Study; HRS, Health and Retirement Study; SALSA, Sacramento Area Latino Study on Aging; PY, person-years; inc., incidence. 